\title{
Title
}

\section{A retrospective and prospective 12 month observational study of the socioeconomic burden of moderate to severe Irritable Bowel Syndrome with Constipation in Spain}

\section{Authors}

Fermín Mearin ${ }^{1}$, Antonio M. Caballero ${ }^{2}$, Jordi Serra ${ }^{3}$, Carles Brotons Cuixart ${ }^{4}$, Ana Tantiñà $^{5}$, Esther Fort-Martorell ${ }^{6}$, Francisco Martínez-Cerezo ${ }^{7}$, Antonia Perelló ${ }^{8}$, Gloria Sánchez-Antolín ${ }^{9}$, Enrique Rey ${ }^{10}$, Ramón Angós Musgo ${ }^{11}$, Ruth Berdier ${ }^{12}$, Blas GómezRodriguez $^{13}$, Pere Clavé ${ }^{14}$, Mónica Garcia-Alonso ${ }^{15}$, Pere Torán-Monserrat ${ }^{16}$, Jan Tack ${ }^{17}$

\section{Affiliations}

1) Centro Médico Teknon, Barcelona

2) Clinica Dr. Caballero, Granada

3) Hospital Universitari Germans Trias i Pujol, Badalona

4) Equip d'Atenció Primària Sardenya. Institut d'Investigació Biomèdica Sant Pau (IIB Sant Pau)

5) CAP Centelles, Centelles

6) Hospital Universitari Dr Josep Trueta, Girona

7) Hospital Universitari Sant Joan de Reus, Tarragona

8) Hospital de Viladecans, Viladecans

9) Hospital Universitario Río Hortega, Valladolid

10) Hospital Clinico San Carlos, Madrid

11) Clínica Universidad de Navarra, Pamplona

12) CAP Vallcarca - Sant Gervasi, Barcelona

13) Hospital Quirón Sagrado Corazón, Sevilla

14) Hospital de Mataró, Mataró; Centro de Investigación Biomédica en Red de enfermedades hepáticas y digestivas (CIBERehd), Instituto de Salud Carlos III.

15) Hospital del Tajo, Aranjuez

16) Unitat de Suport a la Recerca Metropolitana Nord, Institut Universitari d'Investigació en Atenció Primària Jordi Gol (IDIAP Jordi Gol), Mataró, Spain; Health Sciences Research Institute and University Hospital Germans Trias i Pujol, Department of Primary Health Care, Badalona, Spain

17) University of Leuven, Leuven, Belgium

Corresponding author: 
Fermín Mearin. Centro Médico Teknon, Barcelona. Carrer de Vilana, 12, 08022 Barcelona, Spain. mearin@dr.teknon.es 


\section{Abstract}

The socioeconomic burden of irritable bowel syndrome with constipation (IBS-C) has never been formally assessed in Spain.

This 12 month (6-month retrospective and prospective periods) observational, multicentre study assessed the burden of moderate to severe IBS-C in Spain. Patients were included if they had been diagnosed with IBS-C (Rome III criteria) within the last 5 years and had moderate-to-severe IBS-C (IBS Symptom Severity Scale score $\geq 175$ ) severity at inclusion. The primary objective was to assess the direct cost to the Spanish healthcare system (HS).

A total of 112 patients were included, 64 (57\%) of which had severe IBS-C at inclusion. At baseline, a high degree of patients reported abdominal pain and distention (80\% in both cases). Patient quality of life (QoL), measured by the IBS-C QoL and EQ-5D instruments, was found to be impaired with a mean score of 59 and 57 (0-100, worstbest), respectively. Over the 6-month prospective period the mean IBS severity, measured using the IBS-Symptom Severity Scale (IBS-SSS) showed some improvement (315 to 234 [0-500, best-worst]). During the year, $80 \%$ of patients used prescription drugs for IBS-C was substantial, being laxatives the most frequently-prescribed (63\%). The direct cost to the HS was $€ 1,067$, and to the patient was $€ 568$ per year. The total direct cost for moderate to severe IBS-C was $€ 1,635$.

Almost all patients reported continued IBS-C symptoms despite over three-quarters taking medication to treat their IBS-C; overall healthcare resource use and direct costs were asymmetric with a small subset of patients consuming the most resources.

\section{Keywords:}

IBS, IBS-C, direct costs, healthcare resource utilisation, Spain. 


\section{Introduction}

Irritable bowel syndrome (IBS) is a chronic functional bowel disorder with an estimated prevalence of $12 \%$ in Spain and between $5 \%$ - 20\% worldwide. ${ }^{1-3}$ It is characterised by recurrent symptoms of abdominal pain accompanied by altered bowel function. ${ }^{4}$ Subdivision of IBS by the Rome III criteria lists four subtypes: IBS with diarrhoea (IBSD), IBS with constipation (IBS-C), mixed IBS (IBS-M), and unsubtyped IBS (IBS-U). ${ }^{5}$ Disease activity can vary over time, with periods of high disease activity followed by periods of remission. ${ }^{6}$ Similarly, symptoms can change over time and almost half (40\%) of IBS patients can transition from one subtype to another. ${ }^{7}$

Irritable bowel syndrome has been shown to negatively impact quality of life (QoL), for example, affecting sleep, diet, personal/work relationships, and sexual function. ${ }^{5,8}$ The more severe end of the spectrum, moderate to severe IBS, is thought to account for approximately $60 \%$ of all IBS cases and previous studies have shown a substantial economic burden to society through direct medical costs and indirect societal costs. ${ }^{9-11}$

According to the Rome III criteria, the diagnostic criteria for IBS is recurrent abdominal pain or discomfort present for at least three days/month in the last three months accompanied by two or more of the following: improvement with defecation, onset associated with a change in stool frequency, or a change in stool form. ${ }^{12}$ For IBS-C, these characteristics are accompanied by $\geq 25 \%$ of bowel movements being hard or lumpy stools and $<25 \%$ of bowel movements being loose or watery stools. The IBS-C subtype is characterised by constipation, and commonly underdiagnosed due to its similarity to chronic constipation as it shares similar defecation patterns accompanied by occasional abdominal discomfort. ${ }^{13}$ Nevertheless, it is thought that IBS-C affects about $30 \%$ of the IBS population.

Some studies suggest that the current burden of illness for IBS is quite significant. ${ }^{8,14-16}$ Traditional therapies including laxatives, prokinetics, antispasmodics, and bulking agents (such as dietary fibres) are useful for treating constipation in some patients, however, their use is limited due to low overall efficacy and tolerability that is compounded by the fact that as individual treatments they do not treat all the key IBS-C symptoms. ${ }^{17,18}$ Thus, there remains a clear need for more effective therapeutic agents for the treatment of IBS- 
C. To date, linaclotide - a guanylate cyclase-C agonist, is the only licensed pharmacological treatment in Europe for the treatment of IBS-C. ${ }^{19}$

Therefore, the aim of this study was to describe the socioeconomic burden of moderate to severe IBS-C. Here we report the quality of life of patients with IBS-C, the evolution of IBS-C severity over time, and the direct economic costs of IBS-C in Spain.

\section{Patients and Methods}

The study was an observational, 12 month, multicentre study with 6-month retrospective and 6-month prospective components conducted in 6 European countries. Here we report the results of the Spanish population. Patients were included in the study if they were $\geq 18$ years of age, diagnosed with IBS-C in the last 5 years using the Rome III criteria, and had moderate to severe IBS-C at inclusion: defined as an Irritable Bowel Syndrome Symptom Severity Scale (IBS-SSS) score $\geq 175$. The IBS-SSS score was obtained by the sum of the five equally-weighted questions related to pain, distention, bowel dysfunction, and general well-being; each question was scored out of 100 and moderate severity is defined

as an overall score of $\geq 175-300$; severe severity: $>300 .{ }^{20}$ Patients were excluded if they had participated in a clinical trial involving an experimental IBS-C treatment in the six months prior to starting the observational period, or they had an acute or chronic condition that, in the investigator's opinion, would impact the patient's ability to complete the study. This study was conducted in accordance with the Declaration of Helsinki as well as in compliance with ICH GCP guidelines. All ethics committees approved the trial protocol and its amendments.

Patients were screened using medical records in primary and specialist care. Baseline and retrospective data of patients enrolled in the study were obtained from patient interviews and patient medical records, respectively. Demographic, clinical, and QoL data were collected at baseline. Assessment of QoL was performed using the IBS-QoL ${ }^{21}$ and EQ$5 \mathrm{D}^{22}$ instruments. The IBS-QoL included an overall score and eight subscale scores, with 0 indicating the worst QoL and 100 indicating the highest possible QoL. The EQ-5D was a generic measure of health status and consisted of two parts. The first part consisted of five categorical dimensions: mobility, self-care, usual activities, pain/discomfort, and anxiety/depression; these were scored on a 3-point Likert scale. The second part consisted 
of a visual analogue scale (VAS) where 0 indicated the worst health state and 100 indicated the best health state.

Symptom severity was collected using the IBS-SSS at baseline, 3, and 6 months. Healthcare resource utilisation (HRU) data related to IBS-C (medical consultations, hospitalisations, diagnostic tests, therapies, management of adverse reactions) were collected using a questionnaire (specifying whether the costs were public or private). A maximum of 6 months' direct HRU costs were collected at baseline retrospectively. Prospective HRU data were collected during routine follow-up at 3 months ( \pm 0.5 months) and 6 months ( \pm 1 month) /Early Termination. All HRU data were calculated in patients that used the resource.

Direct costs were calculated for the Spanish healthcare system (HS) and the patient's perspective. Consultations, physician visits, and diagnostic tests were estimated from the Listados de Boletines Oficiales de tarifas de Comunidades Autónomas (2005-2011) Hospitalisation costs were estimated from Grupos Relacionados con el Diagnóstico (GRD/DRG) correspondientes and estadísticas. Ministerio de Sanidad, Servicios Sociales e Igualdad (Tarifa AP25, 2008), and Listados de Boletines Oficiales de tarifas de Comunidades Autónomas (2005-2011). Drug costs were estimated from the Ministerio de Sanidad, Servicios Sociales e Igualdad (Nomenclator Digitalis-Integra) and the Consejo General de Colegios Oficiales de Farmacéuticos (Bot Plus, Portalfarma). For the patient's perspective, only the sum of non-prescription medication, complementary therapies, the percentage of HS medications, consultations, hospitalisations, and diagnostic procedures paid for by the patient in each country were taken into account; costs of private consultations and diagnostic procedures were not included.

Exploratory analyses were performed and no confirmatory statistical tests were performed. Demographics, baseline characteristics, HRU characteristics and productivity losses were summarised using descriptive statistics based on non-missing observations. Costs were calculated as a mean with $95 \%$ confidence interval (calculated using 1000 bootstrap samples).

The retrospective, prospective, and combined data periods were analysed separately. The separate analyses were then compared to determine whether there was any statistical difference between them. The data presented here is derived from the combined analysis. 


\section{Results}

A total of 112 patients were enrolled in the study from 4 primary care centres and 12 specialist centres in Spain (Table 1). Over the six month prospective follow up period there were 7 (6.3\%) discontinuations; $6(5.4 \%)$ lost to follow-up and $1(0.9 \%)$ withdrawal due to serious illness.

\section{Demographic, lifestyle and clinical characteristics at baseline}

From the 112 patients that were enrolled in the study, 25 (22.3\%) were recruited from GP centres (all public centres), and 87 (77.7\%) were recruited from specialist centres (59 [52.7\%] from public centres). Baseline patient demographics are shown in Table 1. The average time since IBS-C diagnosis was 2.3 years and patients suffered from IBS-C symptoms for around 10 years. Almost one in five patients had undergone a prior appendectomy/cholecystectomy, and almost one quarter of the total patients had some other form of abdominal surgery.

\section{IBS-C symptoms and quality of life at baseline}

At baseline almost all patients (96.4\%) reported current IBS symptoms (Table 2). Constipation, abdominal pain, and abdominal distention were the most frequently reported symptoms, affecting over three quarters of all patients. Over half of all patients also reported suffering from bloating and abdominal discomfort. Using the IBS-QoL instrument, the most affected domains were food avoidance and health worry. The overall impact of IBS-C on QoL was similar for the IBS-QoL and EQ-5D questionnaires, 59.0 and 56.8 respectively. In addition, over three quarters of patients reporting moderate-tosevere pain/discomfort and over half reported moderate-to-severe anxiety/depression using the EQ-5D categorical dimensions.

\section{Evolution of severity using the IBS-SSS questionnaire}

The severity of the patients IBS-C was assessed three times over the prospective period at three month intervals. The number of patients reporting current abdominal pain and current abdominal distention decreased from $95.5 \%$ and $92.9 \%$ (respectively) at baseline to $85.6 \%$ at 6 months for both categories (Table 3). Using the IBS-SSS VAS the severity of abdominal pain showed the least reduction over 6 months, from mean \pm SD $56.5 \pm 21.4$ 
at baseline to $45.5 \pm 20.4$ at 6 months. By contrast the number of days with abdominal pain and the severity of abdominal pain exhibited the largest reduction, from $5.7 \pm 2.8$ days and $65.0 \pm 23.6$ to $4.4 \pm 2.6$ days and $50.3 \pm 21.7$, respectively. Overall, the total score was observed to decrease by $26 \%$, from $515.4 \pm 82.2$ to $233.9 \pm 97.8$, thus the mean severity decreased from "severe" at baseline to "moderate" at 6 months. Categorically, this observation is demonstrated by the overall reduction in patients with severe IBS-C severity - from $57.1 \%$ of patients at baseline to $20.2 \%$ of patients at 6 months. By contrast, both the number of patients with moderate and mild severity at baseline and 6 months increased from $42.0 \%$ to $53.8 \%$ and $0.0 \%$ to $21.2 \%$, respectively.

\section{Medication use}

Overall, $84.8 \%$ of patients took some form of prescription medication over the 12 months (Table 4). Almost four out of five patients (79.5\%) took prescription medication to treat their IBS-C whereas under half $(42.0 \%)$ of all patients took prescription medication to treat another disease. The most frequently prescribed medication class for IBS-C was laxatives, which were prescribed to almost two thirds of all patients. Antispasmodics and prokinetics were the second and third most prescribed medication classes at $34.8 \%$ and $22.3 \%$ of all patients, respectively. In terms of individual medications, the most frequently prescribed medication was plantago ovata, followed by otilonium bromide, and macrogol plus electrolytes. A high proportion of patients also took some form of non-prescription drug or complementary therapy. Non-prescription drugs were taken by over half of the study population whereas almost a third sought complementary therapies.

\section{Direct cost of IBS-C}

The direct cost of IBS-C was estimated for the HS and for the patient (Table 5). For the HS the largest cost drivers were hospitalisations and medical consultations, which accounted for $50.8 \%$ and $23.3 \%$ of the total costs, respectively. By contrast, pharmacological medications and complementary therapies were the largest drivers for costs to the patients, at $81.2 \%$ and $18.7 \%$ of the total ( $€ 567.6)$, respectively. Overall, pharmacological medications and hospitalisations accounted for $35.3 \%$ and $33.1 \%$ of the total direct costs. The total cost of moderate to severe IBS-C included $€ 1,635$ of direct costs, with patients paying $34.7 \%$ of these costs (Fout! Verwijzingsbron niet 
gevonden.). A comparison of retrospective and prospective data revealed no significant differences between the retrospective and prospective periods.

\section{Discussion}

This is the first study to directly evaluate the socioeconomic impact of moderate to severe IBS-C in Spain. As defined by the Rome III criteria, a positive diagnosis requires IBS-C symptoms to be present for three days per month every three months. During enrolment we observed that almost all patients were currently reporting one or more IBS-C symptom, thus indicating that more severe patients have a high symptom frequency. In terms of QoL, moderate to severe IBS-C patients reported a greater overall QoL impairment compared to studies of IBS patients of all subtypes and severities. ${ }^{8,16,23}$ Studies that predominantly included moderate or severe IBS patients showed the largest similarity in overall QoL score. ${ }^{24-26}$ Assessment of the individual IBS-QoL instrument questions reflected previous observations that the largest impairments in QoL were manifested in terms of dietary restrictions and concern about health. ${ }^{8,16,23-25}$. Similar to the IBS-QoL, the mean score in the EQ-5D VAS was at the lower end of that previously reported for IBS patients (55.3-61.4). ${ }^{8,16,27}$ For the categorical items, similar to the aforementioned studies, few patients reported problems with self-care. Similarly, the most frequently reported problems were pain/discomfort and anxiety/depression. ${ }^{27}$ Combined with the high degree of health worry from the IBS-QoL instrument, the high proportion of patients reporting anxiety or depression provides support to the disorder having an important psychological impact.

At baseline, the mean IBS-SSS score indicated a great severity with an interference with life in general and a dissatisfaction with bowel habits being the most severely affected categories; an observation reflected by the categorical scores from an all-subtype IBS study with a similar overall IBS-SSS score. ${ }^{28}$ Over follow-up, improvements in IBS-C severity were similar to previous studies. ${ }^{29,30}$ The most likely reason for improvement without a specific change in intervention reflects a regression toward the mean and the waxing and waning nature of the disorder.

Prescription drug use was also high for moderate-to-severe IBS-C patients. Surprisingly, IBS-C related medication use was only slightly higher than that reported for moderate to severe all-subtype IBS patients, and yet marginally lower than that reported for IBS 
patients of all subtypes and severities. ${ }^{24}$ Non-prescription drugs were also taken by over half of the patients and an additional third sought complementary therapies, thus suggesting dissatisfaction with current prescription medications.

The largest cost driver for the HS was hospitalisations/ER visits, which was two-fold above the second cost driver - medical consultations - and over three-fold above other costs. Hospitalisations account for $50 \%$ of HS costs, approximately two-fold higher than those previously reported for mixed-severity/all-subtype French IBS patients. ${ }^{14}$ Thus, this suggests that moderate-to-severe IBS-C patients require more inpatient care compared to all-severity patients, however, further comparisons from other countries will be necessary to verify this observation.

Costs to the patient were lower, at approximately half the HS' direct costs. The largest direct costs paid by the patient were medication costs $(81.2 \%)$, followed by complementary therapies (18.7\%). Approximately two-thirds of the total direct costs for IBS-C in Spain were attributable to the HS, with the remaining third being attributable to the patient. The largest drivers of total direct costs for IBS-C in moderate-to-severe patients were medication costs (35.3\%), hospitalisations/ER visits (33.1\%), and consultation costs $(15.2 \%)$. Overall, the costs for hospitalisations/ER visits accounted for a larger proportion of costs than previously reported for mixed-severity IBS/IBS-C patients. ${ }^{3,14,15}$ It is worth noting that the proportion of overall costs attributable to each cost component varied widely between studies and are most likely explained by both the differences in therapeutic management and in reimbursement policies.

In comparison to previous European studies for IBS patients across all severities costs related to moderate-severe patients shown here were substantially higher. ${ }^{3,11,14-16}$

The main limitations of this study were the possibility of healthcare resource underestimation due to approximately three quarters of patients being recruited from specialist care centres. Cost estimations may also be underestimated due to the exclusion of private consultation and diagnostic procedure costs. Furthermore, the partially retrospective nature of the study may be associated with some recall bias. 


\section{Conclusion}

In this study we observed a high socioeconomic impact of moderate to severe IBS-C in Spain. Despite over three-quarters of patients taking medication to treat their IBS-C, almost all patients reported continued IBS-C symptoms. This negatively impacted QoL with a large percentage of patients reporting pain/discomfort and anxiety/depression. The variety of medications prescribed to patients, in combination with a high degree of nonprescription medication and complementary therapy use, suggest that patients are not controlled with currently available therapeutic medications. From an economic perspective, the overall direct cost was highly asymmetrical with few patients consuming a large proportion of healthcare resources. Together, poor QoL and high resource use demonstrates the high socioeconomic cost of this chronic functional bowel disorder. 


\section{Acknowledgements}

The authors would like to thank the IBIS-C study patients for their participation in this trial. Writing support was provided by Jonathan Mackinnon, $\mathrm{PhD}$ from TFS Develop with financial support provided by Allergan International. The study was sponsored and funded by Almirall S.A and subsequent manuscript writing was financially supported by Allergan International.

Declaration of personal interests:

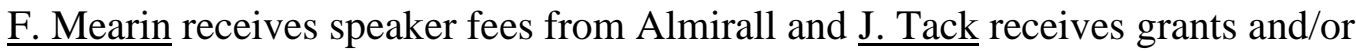
research support from Abbott, Novartis and Shire; honoraria and/or consultancy fees from Almirall, AstraZeneca, Danone, GI Dyamics, GlaxoSmithKline, Ironwood, Janssen, Menarini, Novartis, Rhythm, Shire, Takeda, Theravance, Tsumura, Will Pharma and Zeria; and speaker fees from Abbott, Almirall, AstraZeneca, Janssen, Menarini, Novartis, Shire, Takeda and Zeria. The remaining authors declare no conflicts of interest. Declaration of funding:

This study and all data analyses were funded in full by Almirall, S.A. The preparation of this paper was funded by Almirall, S.A and Allergan International.

Declaration of author contributions:

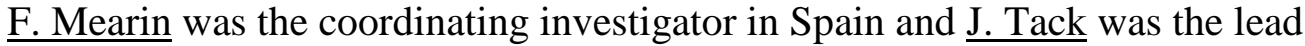
coordinator of the study. AM. Caballero, J. Serra, C. Brotons Cuixart, A. Tantiñà, E. Fort-Martorell, F. Martínez-Cerezo, A. Perelló, G. Sánchez-Antolín, E. Rey, R. Angós Musgo, R. Berdier, B. Gómez-Rodriguez, P. Clavé, M. Garcia-Alonso, and P. ToránMonserrat contributed to clinical data collection. All authors contributed to the creation of the manuscript and all authors revised and approved the final version of the manuscript. 


\section{Bibliography}

1. Mearin F, Badía X, Balboa A, Baró E, Caldwell E, Cucala M, et al. Irritable bowel syndrome prevalence varies enormously depending on the employed diagnostic criteria: comparison of Rome II versus previous criteria in a general population. Scand J Gastroenterol 2001;36:1155-61.

2. Hungin A, Whorwell PJ, Tack J, Mearin F. The prevalence, patterns and impact of irritable bowel syndrome: an international survey of 40000 subjects. Aliment Pharmacol Ther 2003;17:643-50.

3. Quigley EMM, Bytzer P, Jones R, Mearin F. Irritable bowel syndrome: the burden and unmet needs in Europe. Dig Liver Dis Off J Ital Soc Gastroenterol Ital Assoc Study Liver 2006;38:717-23.

4. Lynn RB, Friedman LS. Irritable bowel syndrome. N Engl J Med 1993;329:19405.

5. Drossman DA, Camilleri M, Mayer EA, Whitehead WE. AGA technical review on irritable bowel syndrome. Gastroenterology 2002;123:2108-31.

6. Weinland SR, Morris CB, Hu Y, Leserman J, Bangdiwala SI, Drossman DA. Characterization of Episodes of Irritable Bowel Syndrome Using Ecological Momentary Assessment. Am J Gastroenterol 2011;106:1813-20.

7. Engsbro AL, Simren M, Bytzer P. Short-term stability of subtypes in the irritable bowel syndrome: prospective evaluation using the Rome III classification. Aliment Pharmacol Ther 2012;35:350-9.

8. Paré P, Gray J, Lam S, Balshaw R, Khorasheh S, Barbeau M, et al. Health-related quality of life, work productivity, and health care resource utilization of subjects with irritable bowel syndrome: Baseline results from logic (longitudinal outcomes study of gastrointestinal symptoms in Canada), a naturalistic study. Clin Ther. 2006;28:1726-35.

9. Drossman DA, Chang L, Bellamy N, Gallo-Torres HE, Lembo A, Mearin F, et al. Severity in irritable bowel syndrome: a Rome Foundation Working Team report. Am J Gastroenterol;106:1749-59.

10. Hungin AP., Tack J, Mearin F, Whorwell J, Dennis E, Barghout V. Irratable bowel syndrome (IBS): prevalence and impact in the USA - the truth in IBS (T-IBS) survey. Am J Gastroenterol 2002;97:S280-1.

11. Wells NE, Hahn BA, Whorwell PJ. Clinical economics review: irritable bowel syndrome. Aliment Pharmacol Ther 1997;11:1019-30.

12. Longstreth GF, Thompson WG, Chey WD, Houghton LA, Mearin F, Spiller RC. Functional bowel disorders. Gastroenterology 2006;130:1480-91.

13. Mearin F, Rey E, Balboa A. [Functional and motor digestive disorders]. Gastroenterol Hepatol 2013;36 Suppl 2:3-14. 
14. Le Pen C, Ruszniewski P, Gaudin A -F., Amouretti M, Bommelaer G, Frexinos J, et al. The burden cost of French patients suffering from irritable bowel syndrome. Scand J Gastroenterol 2004;39:336-43.

15. Müller-Lissner SA, Pirk O. Irritable bowel syndrome in Germany. A cost of illness study. Eur J Gastroenterol Hepatol 2002;14:1325-9.

16. Akehurst RL, Brazier JE, Mathers N, O'Keefe C, Kaltenthaler E, Morgan A, et al. Health-related quality of life and cost impact of irritable bowel syndrome in a UK primary care setting. PharmacoEconomics 2002;20:455-62.

17. Jadallah KA, Kullab SM, Sanders DS. Constipation-predominant irritable bowel syndrome: A review of current and emerging drug therapies. World J Gastroenterol WJG 2014;20:8898-909.

18. Tack J, Fried M, Houghton LA, Spicak J, Fisher G. Systematic review: the efficacy of treatments for irritable bowel syndrome - a European perspective. Aliment Pharmacol Ther 2006;24:183-205.

19. Layer P, Stanghellini V. Review article: linaclotide for the management of irritable bowel syndrome with constipation. Aliment Pharmacol Ther;39:371-84.

20. Francis CY, Morris J, Whorwell PJ. The irritable bowel severity scoring system: a simple method of monitoring irritable bowel syndrome and its progress. Aliment Pharmacol Ther 1997;11:395-402.

21. Drossman DA, Patrick DL, Whitehead WE, Toner BB, Diamant NE, Hu Y, et al. Further validation of the IBS-QOL: a disease-specific quality-of-life questionnaire. Am J Gastroenterol 2000;95:999-1007.

22. Bushnell DM, Reilly MC, Galani C, Martin ML, Ricci J-F, Patrick DL, et al. Validation of electronic data capture of the Irritable Bowel Syndrome--Quality of Life Measure, the Work Productivity and Activity Impairment Questionnaire for Irritable Bowel Syndrome and the EuroQol. Value Health $J$ Int Soc Pharmacoeconomics Outcomes Res 2006;9:98-105.

23. Kanazawa M, Drossman DA, Shinozaki M, Sagami Y, Endo Y, Palsson OS, et al. Translation and validation of a Japanese version of the irritable bowel syndromequality of life measure (IBS-QOL-J). Biopsychosoc Med 2007;1:6.

24. Drossman DA, Morris CB, Schneck S, Hu YJ, Norton NJ, Norton WF, et al. International survey of patients with IBS: Symptom features and their severity, health status, treatments, and risk taking to achieve clinical benefit. J Clin Gastroenterol 2009;43:541-50.

25. Schmulson M, Ortiz O, Mejia-Arangure JM, Hu YB, Morris C, Arcila D, et al. Further validation of the IBS-QOL: female Mexican IBS patients have poorer quality of life than females from North Carolina. Dig Dis Sci 2007;52:2950-5.

26. Spiegel B, Harris L, Lucak S, Mayer E, Naliboff B, Bolus R, et al. Developing valid and reliable health utilities in irritable bowel syndrome: results from the IBS PROOF Cohort. Am J Gastroenterol 2009;104:1984-91. 
27. Bushnell DM, Martin ML, Ricci J-F, Bracco A. Performance of the EQ-5D in Patients with Irritable Bowel Syndrome. Value Health 2006;9:90-7.

28. Miller V, Carruthers HR, Morris J, Hasan SS, Archbold S, Whorwell PJ. Hypnotherapy for irritable bowel syndrome: an audit of one thousand adult patients. Aliment Pharmacol Ther 2015;41:844-55.

29. Mearin F, Baró E, Roset M, Badía X, Zárate N, Pérez I. Clinical patterns over time in irritable bowel syndrome: symptom instability and severity variability. Am J Gastroenterol 2004;99:113-21.

30. Drossman DA, Morris CB, Hu Y, Toner BB, Diamant N, Leserman J, et al. A prospective assessment of bowel habit in irritable bowel syndrome in women: defining an alternator. Gastroenterology 2005;128:580-9. 
Table 1: Patient Demographics

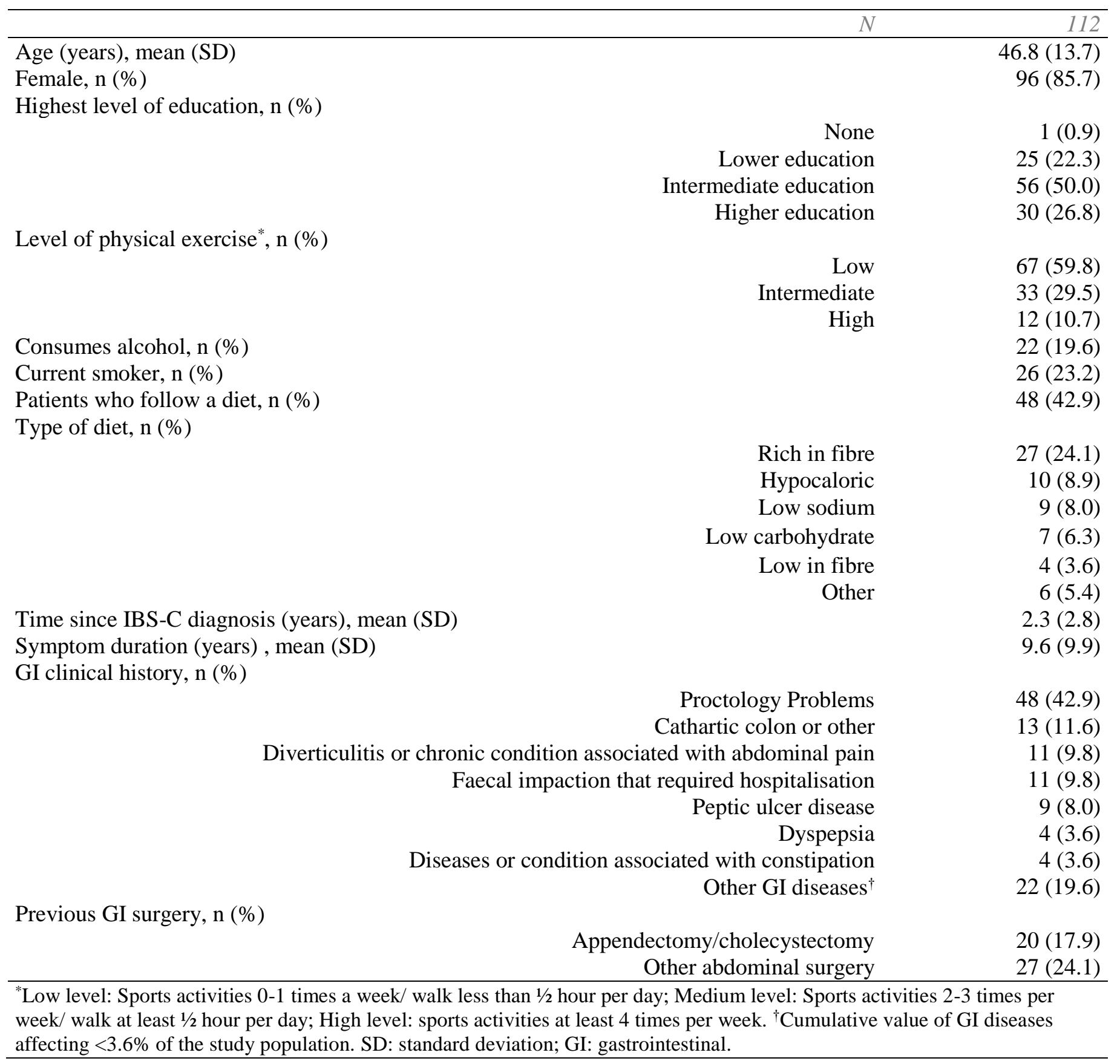


IBS-C symptoms questionnaire, n (\%)

$\begin{array}{rr}\text { Any IBS-C symptom } & 108(96.4) \\ \text { Constipation } & 94(83.9) \\ \text { Abdominal pain } & 89(79.5) \\ \text { Abdominal distention } & 89(79.5) \\ \text { Bloating } & 66(58.9) \\ \text { Abdominal discomfort } & 65(58.0) \\ \text { Straining } & 30(26.8) \\ \text { Swollen stomach } & 29(25.9) \\ \text { Diarrhoea } & 13(11.6) \\ \text { Other }^{*} & 4(3.6)\end{array}$

IBS-QoL questionnaire score, mean (SD) ${ }^{\dagger}$

$\begin{array}{rr}\text { Food Avoidance } & 39.6(24.2) \\ \text { Health Worry } & 45.4(26.9) \\ \text { Dysphoria } & 56.5(25.8) \\ \text { Interference with Activity } & 59.1(23.2) \\ \text { Body Image } & 61.1(23.8) \\ \text { Social Reaction } & 68.9(27.8) \\ \text { Sexual concern } & 73.5(32.9) \\ \text { Relationships } & 76.5(24.4) \\ \text { Overall } & 59.0(21.2)\end{array}$

Number of patients with impairment in EQ-5D categorical domains, $\mathrm{n}(\%)$

\begin{tabular}{rr} 
Mobility & $20(17.9)$ \\
Self-care & $4(3.6)$ \\
Usual activities & $34(30.4)$ \\
Pain/discomfort & $96(85.7)$ \\
Anxiety/Depression & $70(62.5)$ \\
& $56.8(20.9)$ \\
\hline
\end{tabular}




\begin{tabular}{rrrrr}
\hline & & Baseline & Visit 2 & Visit 3 \\
& $N$ & 112 & 108 & 104 \\
\hline IBS-SSS categorical item scores, $\mathrm{n}(\%)$ & & & & \\
& & & & \\
Current abdominal pain & $107(95.5)$ & $89(82.4)$ & $89(85.6)$ \\
Current abdominal distention & $104(92.9)$ & $91(84.3)$ & $89(85.6)$
\end{tabular}

IBS-SSS VAS and overall scores, mean (SD)

$\begin{array}{rrrr}\text { Severity of abdominal pain }^{* 1} & 56.5(21.4) & 47.7(20.1) & 45.5(20.4) \\ \text { Number of days with abdominal pain }^{\dagger 2} & 5.7(2.8) & 4.8(2.8) & 4.4(2.6) \\ \text { Severity of abdominal distention }^{* 3} & 65.0(23.6) & 55.7(22.3) & 50.3(21.7) \\ \text { Dissatisfaction with bowel habits }^{*} & 77.9(19.6) & 60.8(22.0) & 60.6(22.8) \\ \text { Interference with life in general }^{*} & 71.4(21.0) & 59.4(21.8) & 56.3(23.3) \\ \text { IBS-SSS total score } & 315.4(82.2) & 240.4(99.3) & 233.9(97.8)\end{array}$

Categorical severity of IBS-C (IBS-SSS), n (\%)

\begin{tabular}{rrrr} 
Mild $(<175)$ & $0(0)$ & $18(16.7)$ & $22(21.2)$ \\
Moderate $(175 \leq 300)$ & $47(42.0)$ & $54(50.0)$ & $56(53.8)$ \\
Severe $(>300)$ & $64(57.1)$ & $30(27.8)$ & $21(20.2)$ \\
\hline
\end{tabular}

$* 0-100$; best to worst. ${ }^{\dagger}$ in every10 days. ${ }^{\ddagger} 0-500$; best to worst. ${ }^{1} \mathrm{~N}=99 / 81 / 87 .{ }^{2} \mathrm{~N}=107 / 85 / 84 .{ }^{3} \mathrm{~N}=103 / 90 / 89$. IBS-SSS: IBSsymptom severity scale; VAS: visual analogue scale; SD: standard deviation. 
\begin{tabular}{l}
\hline \\
Any prescription drug, $\mathrm{n}(\%)$ \\
IBS-C prescription drug, $\mathrm{n}(\%)$ \\
Prescription drug for other diseases, $\mathrm{n}(\%)$ \\
IBS-C prescription medication group, $\mathrm{n}(\%)$
\end{tabular}

N

$95(84.8)$

89 (79.5)

47 (42.0)

(1)

Individual IBS-C prescription drugs n (\%)

$\begin{array}{rr}\text { Laxatives } & 70(62.5) \\ \text { Antispasmodics } & 39(34.8) \\ \text { Prokinetics } & 25(22.3) \\ \text { Antidepressants } & 4(3.6) \\ \text { Analgesics } & 3(2.7) \\ \text { Other* } & 10(8.9)\end{array}$

Plantago ovata

33 (34.7)

Otilonium bromide

$21(22.1)$

Macrogol plus electrolytes

$12(12.6)$

Cinitapride tartrate

$9(9.5)$

Magnesium hydroxide

$8(8.4)$

Mebeverine

$8(8.4)$

Lactulose

$6(6.3)$

Macrogol

$5(5.3)$

Pinaverium bromide

$5(5.3)$

Agiolax

4 (4.2)

Bisacodyl

4 (4.2)

Domperidone

4 (4.2)

Flatoril

4 (4.2)

4 (4.2)

Hyoscine butylbromide

4 (4.2)

Mebeverine hydrochloride

$4(4.2)$

Prucalopride succinate

$63(56.3)$

Non-prescription drugs for IBS-C, $\mathrm{n}(\%)$

Other $^{\dagger}$

*Includes medications not prescribed as analgesics, antidepressants, antispasmodics, laxatives or prokinetics. ${ }^{\dagger}$ Includes medications used by $<4.2 \%$ of patients. 


\begin{tabular}{|c|c|c|c|}
\hline$N$ & $\begin{array}{l}\text { HS } \\
112 \\
\end{array}$ & $\begin{array}{r}\text { Patient } \\
112 \\
\end{array}$ & $\begin{array}{r}\text { Total } \\
112 \\
\end{array}$ \\
\hline \multicolumn{4}{|l|}{ Medical consultations $(€)$} \\
\hline Mean $(95 \%$ CI $)$ & $249.0(198.3,311.7)$ & $0.0(0.0,0.0)$ & $249.0(198.3,311.7)$ \\
\hline Min-Max & $0.0-2,311.0$ & $0.0-0.0$ & $0.0-2,311.0$ \\
\hline Median & 153.0 & 0.0 & 153.0 \\
\hline \multicolumn{4}{|l|}{ Hospitalisations $(€)$} \\
\hline Mean $(95 \% \mathrm{CI})$ & $541.9(285.9,849.8)$ & $0.0(0.0,0.0)$ & $541.9(285.9,849.8)$ \\
\hline Min-Max & $0.0-8,614.0$ & $0.0-0.0$ & $0.0-8,614.0$ \\
\hline Median & 0.0 & 0.0 & 0.0 \\
\hline \multicolumn{4}{|l|}{ Diagnostic tests $(€)$} \\
\hline Mean $(95 \%$ CI) & $159.4(109.5,215.2)$ & $0.0(0.0,0.0)$ & $159.4(109.5,215.2)$ \\
\hline Min-Max & $0.0-1,474.0$ & $0.0-0.0$ & $0.0-1,474.0)$ \\
\hline Median & 0.0 & 0.0 & 0.0 \\
\hline \multicolumn{4}{|l|}{ Pharmacological medications $(€)$} \\
\hline Mean $(95 \% \mathrm{CI})$ & $116.5(34.5,227.6)$ & $460.9(239.5,716.8)$ & $577.3(328.5,848.3)$ \\
\hline Min-Max & $0.0-4,772.0$ & $0.0-7,372.0$ & $0.0-7,372.0$ \\
\hline Median & 0.0 & 61.5 & 123.0 \\
\hline \multicolumn{4}{|l|}{ Complementary therapies $(€)$} \\
\hline Mean $(95 \% \mathrm{CI})$ & $0.0(0.0,0.0)$ & $106.3(57.9,178.8)$ & $106.3(57.9,178.8)$ \\
\hline Min-Max & $0.0-0.0$ & $0.0-2,640.0$ & $0.0-2,640.0$ \\
\hline Median & 0.0 & 0.0 & 0.0 \\
\hline \multicolumn{4}{|l|}{ Adverse reactions $(€)$} \\
\hline Mean $(95 \% \mathrm{CI})$ & $0.6(0.0,1.9)$ & $0.5(0.0,1.3)$ & $1.1(0.0,2.7)$ \\
\hline Min-Max & $0.0-71.0$ & $0.0-36.0$ & $0.0-71.0$ \\
\hline Median & 0.0 & 0.0 & 0.0 \\
\hline \multicolumn{4}{|l|}{ TOTAL DIRECT COSTS (€) } \\
\hline Mean $(95 \%$ CI $)$ & $1,067.3(729.6,1,446.6)$ & $567.6(333.1,840.7)$ & $1635.0(1,226.0,2,061.4)$ \\
\hline Min-Max & $0.0-9,680.0$ & $0.0-8,092.0$ & $0.0-10,782.0$ \\
\hline Median & 262.5 & 103.5 & 518.5 \\
\hline
\end{tabular}

